\title{
The interference of Newcastle, avian influenza and infectious bursal disease vaccines with the efficiency of IB vaccine in broiler chicks by using quantitative RT-PCR test
}

\author{
R.H.S. Rabee* and I.M. Jaber \\ Department of Pathology and Poultry Diseases, College of Veterinary Medicine, University of Al-Qasim Green, Babil, Iraq \\ *E.mail: raaidhsr@yahoo.com
}

(Received March 29, 2018; Accepted May 2, 2018)

\begin{abstract}
This study was conducted to investigate the effects the interference of ND, AI, IBD vaccines on efficacy of the IBV vaccination program (H120 and Ma5). Three hundred broiler chicks (Ross308) from Al-Haddi hatchery / Babel province were divided randomly into three equal groups, each group contain 100 chicks and treated as follows: the $1^{\text {st }}$ group; IB vaccine (H120) was given at one day old by intranasal and ocular drop methods, IB vaccine Ma5 strain vaccine was given at age 14 days by spray method. The $2^{\text {nd }}$ group at one day old IB H120 + ND LaSota alive vaccines strain was given by intranasal and ocular drop method, also given mixed killed vaccine contain ND with AI by S/C injection. At 10 days old alive ND vaccine LaSota strain gives by drinking water. At 12 in day old attenuated IBD vaccine gives by drinking water. At day old IB Ma5 strain vaccine was given using spray method. The $3^{\text {ed }}$ group: control group without vaccine. Blood samples were collected from jugular vein at 1, 7, 14,21,28, 35 and 40 day old to determine the antibody titer against IBV by ELISA test and samples were taken from trachea and kidney for Real- time quantitative -PCR (viral load) at 21 and 35 days old. All groups were challenged with local virulent IBV isolate (IBV CH Babylon F2 2013) $100 \times 10^{6.5} \mathrm{ELD}_{50} / \mathrm{ml}$ at 28 days old by ocular and intranasal drop method. Morbidity and mortality were recorded in all the challenged birds. The result show that the significant differences between all groups in different parameters at $\mathrm{P}<0.05$.
\end{abstract}

Keywords: AIV, NDV, IBDV, Viral load, Immune response

Available online at http://www.vetmedmosul.com

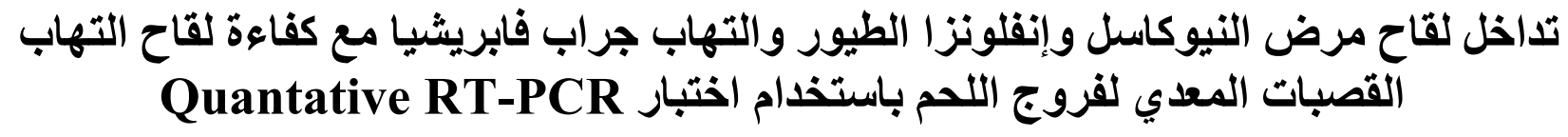

$$
\begin{aligned}
& \text { رائد حسين صالح و عصام عحمد جابر } \\
& \text { فرع الأمر اض و أمر اض الدواجن، جامعة القاسم الخضر اء، كلية الطب البيطري، بابل، العر اق }
\end{aligned}
$$

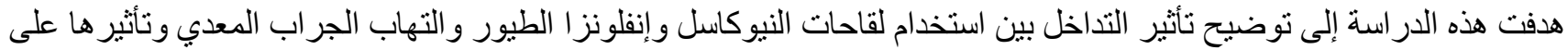

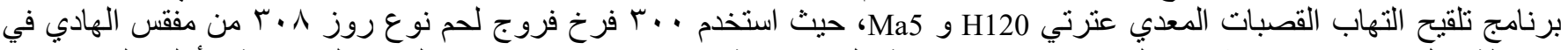

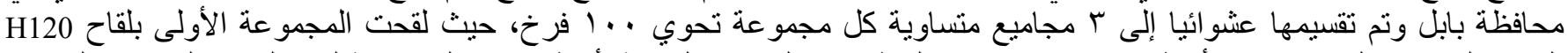

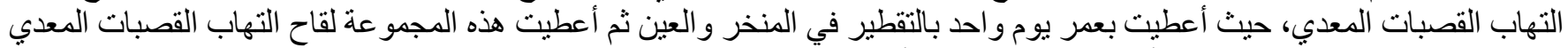

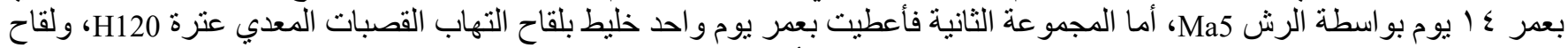

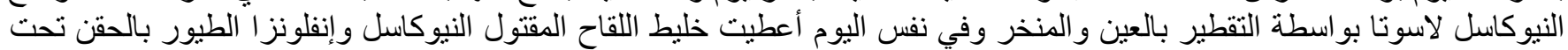

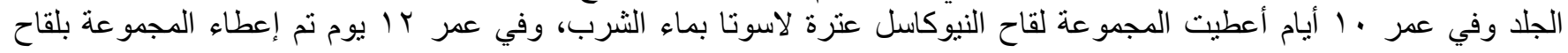




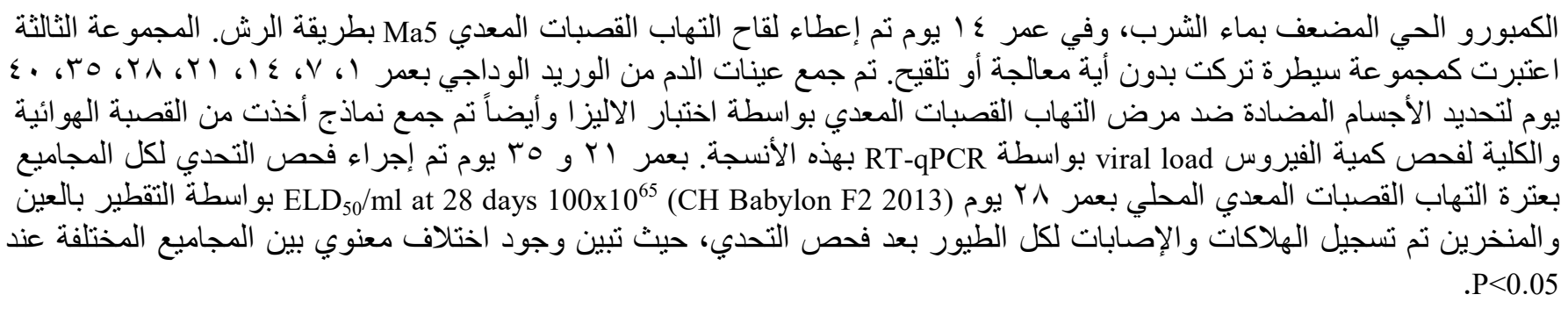

\section{Introduction}

Infectious bronchitis was first described by Schalk and Hawn in 1931 in North Dakota as a new respiratory disease of chickens, Infectious bronchitis (IB) is an acute highly contagious disease of chickens caused by a virus belonging to the genus Corona virus of the Family Coronaviridae characterized by depression, tracheal rales, sneezing, coughing, wet frothy eyes with conjunctivitis and high morbidity and mortality as well as secondary infection (1). IB causing significant economic loses to the poultry industry in worldwide (2). Out breaks of IB frequently occurs in the field in many countries because the virus has a tendency of frequent mutations many variants strain with changes in the genome have been identified (3). The mutations are natural mechanisms of defense of the virus, trying to avoid the immune system defenses in chickens, these resulting "variant" strains have new neutralizing epitopes that may not be recognized by the antibodies exerted by the use of the current vaccines the presence of cross-protection produced by some IBV serotypes against antigenically unrelated strains (variants) is unpredictable (4). The interference between IBV and NDV, AIV, occurred because both of them infect initially the epithelial cells of respiratory tract and then replicate in the cell cytoplasm (5). The aim of the present study to exploring the interference of Newcastle disease, Infectious Bursal Disease and Avian Influenza vaccines on the efficiency of IB vaccination program and analysis of viral RNA copies (viral load) in the tracheal and kidney tissues after and before challenge with highly virulent IBV indicated this assay may be a reliable indicator of infection or/and protection of chicken.

\section{Materials and methods}

Three hundred, one day old broiler chicks from AlHaddi hatchery at Babel province (Ross 308), were divided randomly into three groups (each group contain 100 chicks) by plastic barriers and the ground mattress with wood shavers litter and supplemented all management requirements as poultry hygiene standardization, and were treated as follow: G1 was given H120 vaccine at one day old by intranasal and ocular drop method, Ma5 strain vaccine was given at age 14 days by spray method. G2 received at one day old IB H120 + ND LaSota attenuated vaccines strain was given by intranasal and ocular drop method, also given mixed killed vaccine contain ND + AI by $\mathrm{S} / \mathrm{C}$ injection, at 10 days old attenuated ND vaccine LaSota strain were orally administration, at 12 day old attenuated IBD vaccine were orally administration, at age 14 day old IB Ma5 strain vaccine was given using spray method. G3 not vaccinated considered as control group. Table 1 explain the vicinal viral strain.

Table 1: Viral strains used in vaccination programs

\begin{tabular}{lc}
\hline Strain & Source (Origin) \\
\hline IBV CEVAC BRON H120 & CEVA - Hungary \\
$\left(1 \times 10^{6.5} \mathrm{EID}_{50}\right)$ & \\
IBV MA5 Massachusetts & Intervet - Holland \\
$\left(1 \times 10^{3.5} \mathrm{EID}_{50}\right)$ & Intervet - Holland \\
NDV LaSota $\left(1 \times 10^{6} \mathrm{EID}_{50}\right)$ & Intervet - Holland \\
NOBLIS NDV+ AIV oil emulsion & CEVA - Hungary \\
IBDV intermediate plus & \\
$\left(1 \times 10^{2.7}\right.$ EID $\left._{50}\right)$ & \\
\hline
\end{tabular}

\section{Enzyme Linked Immunosorbent Assay (ELISA) for IBV antibody titer}

Blood samples were collected from jugular vein at 1,7 , $14,21,28,35$ and 40 to determine the antibody titer against IBV by ELISA test (Indirect method). The procedure used in this test was performed according to the manufacturer instructions (ProFLOK ${ }^{\circledR}$ IBV ELISA Kit Synbiotics-USA).

\section{Avian Infectious Bronchitis dtec-RT-qPCR Test Description (viral load)}

Quantitative RT-PCR (viral load) at 21 and 35 days old using AIBV dtec-RT-qPCR Test comprises a series of species-specific targeted reagents designed for Avian Infectious Bronchitis Virus (AIBV) detection by using qPCR according to manufacturer company genetic PCR solution (GPS) Spain 24-965409001.

\section{Challenge test with local field isolated IBV}

Velogenic local field virulent isolate (IBV CH Babylon $\mathrm{F}_{2}$ 2013) $100 \times 10^{6.5}$ EID $50 / \mathrm{ml}$ of IBV was used as a challenge virus at 28 days by giving EID $_{50}$ which was 
determined according to Reed and Muench (6). Morbidity and mortality were recorded in all the challenged birds were observed daily for 10 days post challenge.

\section{Results}

\section{Interference of ND, AI and IBD vaccine with the efficiency of IB vaccine}

However, the antibody titers of vaccinated groups (G1 and G2) revealed significant differences at $\mathrm{P}<0.05$ compared to the non-vaccinated groups (G3). After challenge at the age of 28 days, G1 showed the highest antibody titer at the age of 35 and 40 days (1887.8 and
3155) compared to other groups; these differences were significant at $\mathrm{P}<0.05$ (Table 2).

\section{Clinical signs and mortality of chickens}

The results of the current study explained that vaccinating the first group with booster dose of IBV (H120 and Ma5) gave least clinical signs and low mortality percentage followed by other vaccinated group (second) that's vaccinated with different type of vaccine, which recorded moderate percentage in comparison with nonvaccinated group (third) control group which registered the highest percentage in clinical signs and mortality (Table 3).

Table 2: The interference of the different type of vaccines (NDV, IBD and AI) with vaccinated against infectious bronchitis virus after challenge with the local felid isolate (IB CH Babylon $\mathrm{F}_{2}$ 2013)

\begin{tabular}{cccccccc}
\hline & \multicolumn{7}{c}{ IBV antibody titer (means \pm SE) $\mathrm{n}=5$} \\
& 1 Day & 7 Days & 14 Days & 21 Days & 28 Days & 35 Days & 40 Days \\
\hline \multirow{2}{*}{ G1 } & & $2411.2 \pm 13.01$ & $1918.2 \pm 16.32$ & $3177.4 \pm 14.1$ & $3461 \pm 18.14$ & $1887.8 \pm 34.8$ & $3155 \pm 59.3$ \\
& Maternal & A & A & A & A & A & A \\
G2 & Immunity & $2214.6 \pm 15.54$ & $1711.4 \pm 17.56$ & $2797.8 \pm 14.74$ & $3091.4 \pm 27.95$ & $1622.6 \pm 40.3$ & $2838.8 \pm 57.19$ \\
& $5400 \pm 14.5$ & A & B & B & B & B & B \\
G3 & & $1579.2 \pm 16.31$ & $422.8 \pm 21.8$ & $308.4 \pm 30.4$ & $0 \pm 0$ & $0 \pm 0$ & $759.4 \pm 18.3$ \\
& & C & C & C & C & C & C \\
\hline
\end{tabular}

The different capital litter in columns refer to significant differences at $\mathrm{P}<0.05$ among groups.

Table 3: Development of clinical signs and mortalities post challenge with IBVs at 28 days of age

\begin{tabular}{lcc}
\hline Groups & Morbidity \% & Mortality \% \\
\hline G1 & $50^{\mathrm{B}}$ & $20^{\mathrm{B}}$ \\
G2 & $60^{\mathrm{B}}$ & $25^{\mathrm{B}}$ \\
G3 & $100^{\mathrm{A}}$ & $70^{\mathrm{A}}$ \\
\hline
\end{tabular}

Number of chicks groups $=30$, the different capital letters refer to significant differences between different columns $(\mathrm{P}<0.05)$.

Table 4: Viral load of IBV in the trachea and kidney detection by real-time RT-qPCR test (RNA copies number / $20 \mathrm{mg}$ tissue)

\begin{tabular}{ccccc}
\hline \multirow{5}{c}{ Organ } \\
\cline { 2 - 5 } & \multicolumn{2}{c}{ Trachea } & \multicolumn{2}{c}{ Kidney } \\
\cline { 2 - 5 }$\Xi_{\infty}$ & 21 days & 35 days & 21 days & 35 days \\
\hline 1 & $1336.6 \pm 34.9$ & $2530.1 \pm 52.8$ & $81.8 \pm 8.8$ & $3326.1 \pm 122.4$ \\
& $\mathrm{~A}$ & $\mathrm{C}$ & $\mathrm{A}$ & $\mathrm{B}$ \\
& $1281.8 \pm 56.06$ & $2147.1 \pm 41.08$ & $48.8 \pm 8.05$ & $3102.5 \pm 111.9$ \\
2 & $\mathrm{~A}$ & $\mathrm{~B}$ & $\mathrm{~B}$ & $\mathrm{~B}$ \\
& $0 \pm 0$ & $6997.3 \pm 93.5$ & $0 \pm 0$ & $7116.6 \pm 83.6$ \\
3 & $\mathrm{~B}$ & $\mathrm{~A}$ & $\mathrm{C}$ & $\mathrm{A}$ \\
\hline
\end{tabular}

The different capital litter in columns refer to significant differences $(\mathrm{P}<0.05)$ among groups.
Results of IB viral load detection by real-time RT-qPCR

The results of this study were showed that before challenge vaccinated groups G1 and G2 have significant differences at $\mathrm{P}<0.05$ compared to the non-vaccinated groups G3, but after challenge both G1and G3 had less significant differences at $\mathrm{P}<0.05$ compared with G3 (Table $4)$.

\section{Discussion}

The results of the present study of Interference of ND, AI and IBD vaccine with the efficiency of IB vaccine reflected decrease in antibody titer against IBV in the G2 compared with G1, this finding agree with the studies of Gelb et al. and Montgomery et al. $(7,8)$ they explained that the interference between IBV and NDV occurred because both of them infects initially the epithelial cells of respiratory tract and then replicate in the cell cytoplasm, it also agree with the studies performed by Cook et al. (9) who used combined or IBV and NDV vaccinations showed that IBV vaccination causes a decrease in the capacity of the harderian gland to respond to antigenic stimulus. Therefore, the reduced immune response by harderian gland induced by IBV may then decrease anti-NDV antibody levels if vaccination has been performed with IBND combined vaccines. Montgomery et al. (8) reported that IBV interferes with NDV when mixed vaccine in field as 
compared with preparation in laboratory, therefore causes reduced immune response against IBV.

The results of clinical signs followed by quantitative assessment of viral load at 5 days after challenge for evaluation of protection as reported by Cook et al (9). Clinical signs percentages observed on chicks in groups challenged with Babylon isolate are 100\% similar. So H120 and Ma5 (Mass serotype) could provide partial protection against IBV. Regarding the remaining Iraqi isolates based on the S1 sequence, there was no homology reported between them and the vaccine used so the vaccine provided only limited protection against them. This result is in agreement with finding that reports of in vivo cross protection often declines with decreasing S1 sequence homology between vaccinal strain and strains used in challenge. Montgomery et al (8) concluded that the ND, AI and IBD vaccine interference with immune response against infectious bronchitis vaccine.

While the results of IB viral load detection by real-time RT-qPCR before and after challenge with the local isolate, could be related to the fact that the Iraqi isolate has relevant differences in its amino acid sequence of S1 glycoprotein with regard to H120 and Ma5 strains. Therefore, the degree of cross-protection tends to reduce as decreasing the extent of the characteristics of the amino acid sequences of S1 glycoprotein from two different strains of IBV (10).

The increment RNA copies number in at day 21 returned to replicate the vaccinal virus in upper respiratory tract especially after booster dose at 14 days old chicks. This finding agreed with Cook et al.(11), who hypothesized that the distinct predominant phenotypes present in IBVderived vaccines from different companies would show a different behavior in the host; i.e. showed different pathogenicity in the upper respiratory tract of vaccinated chickens, and found significantly higher $(\mathrm{P}<0.05)$ viral loads 5 and 8 days post-vaccination (DPV) in tear fluids of chickens vaccinated with $\mathrm{A}, \mathrm{B}, \mathrm{C}$ and $\mathrm{D}$ vaccines. Also, this agrees with Asli et al (12), who found an increase in IBV vial copy 4 day in tracheal collected sample after vaccination one day old and reached peak at 7 days after vaccination.

The results of RT-qPCR showed that the viral loads were higher in the kidney than in the trachea, for both vaccinated and non-vaccinated groups at day 35 after challenge at 28 days old chicks. Such finding reinforces the nephropathogenic character of this Iraqi IBV isolate. The results of RT-qPCR also showed that there was a significant difference in the mean number of S1 gene copy in the tracheal samples of vaccinated group and that showed by non-vaccinated group $(\mathrm{P}<0.05)$. Likewise, the mean viral load detected in the kidneys from birds of non-vaccinated group was higher, and showed a significant difference compared to that observed in the vaccinated group $(\mathrm{P}<0.05)$.
It is known that the IBV S1 glycoprotein is largely responsible for the tissue tropism of an IBV strain (13). This glycoprotein plays a critical role in the viral infectivity and contains the antigenic determinants that induce the formation of neutralizing antibodies. Thus, the variation in the composition of amino acids located in some regions of the $\mathrm{S} 1$ glycoprotein could result in change in tissue tropism, virulence and antigenicity of a given IBV strain and constitutes the main strategy for IBV escapes from the host defense mechanisms $(8,9,14)$.

This study assessed the immune-protection status induced by the conventional Massachusetts IBV strain (H120 and Ma5) against this Iraqi variant isolate. The results indicated that there was a good vaccine protection in the trachea due to lower pathogenicity of this Iraqi variant isolate for this organ as compared to the kidney. For the best protection against virulent challenge with nephropathogenic IBV strain is usually achieved by vaccination with homologous serotype strain (15).

\section{Reference}

1. Faruku B, Siti SA, Abdul Rahman O, Mohd HB, Muhammad AS, Abbal Y. Pathogenesis and diagnostic approaches of Avian Infectious Bronchitis. Res Vet Sci. 2016;23:344.

2. Promkuntod N, van Eijndhoven REW, de Vrieze G, Grone A, Verheije MH. Mapping of the receptor binding domain and amino acids critical for attachment in the spike protein of avian coronavirus infectious bronchitis virus. Virolo. 2014;448:26-32.

3. Susan SM, Salama E, Ahmed A. Efficacy of some living classical and variant infectious bronchitis vaccines against local variant isolated from Egypt. Nat Sci. 2012;10(12):292-299.

4. Al-Bbawi FH. Isolation and molecular characterization of local infectious bronchitis virus with evaluation of immunological responses to some infectious bronchitis virus vaccines with betaglucan in broiler. [PhD dissertation]. Baghdad: Baghdad University; 2015.

5. Cavanagh D. Coronavirus avian infectious bronchitis virus. Vet Res. 2007;38(2):281-97.

6. Reed LJ, Muench H. A simple method of estimating fifty per cent endpoints. Am J Hyg. 1983;27:493-497.

7. Gelb J, Weisman Y, Ladman B, Meir R. S1 gene characteristics and efficacy of vaccination against infectious bronchitis virus field isolates from the United States and Israel (1996 to 2000). Avi Pathol. 2005;34:194-203.

8. Montgomery YR, Maslin WR, Boyle CR. Effects of Newcastle disease vaccines and Newcastle disease/infectious bronchitis combination vaccines on the head-associated lymphoid tissues of the chicken. Avi Dis. 1997;41(2):399-406.

9. Cook J, Chesher J, Baxendale W, Greenwood N, Huggins M, and Orbell S. Protection of chickens against renal damage caused by nephropathogenic infectious bronchitis virus. Avi Pathol. 2001;30:423-426.

10. Cavanagh D, Ellis MM, Cook JK. Relationship between sequence variation in the S1 spike protein of Infectious Bronchitis Virus and the extent of cross-protection in vivo. Avi Pathol. 1997;26:63-74.

11. Cook JK, Orbell SJ, Woods MA, Huggins MB. Breadth of protection of the respiratory tract provided by different live-attenuated infectious bronchitis vaccines against challenge with infectious bronchitis viruses of heterologous serotypes. Avi Pathol. 1999;28:477-485.

12. Asli MM, Hosseini SA, Lotfollahian H, Shariatmadari F. Effect of probiotics, Yeast, Vitamin E and Vitamin C supplements on 
performance and immune response of laying hen during high environmental temperature. Int J Poult Sci. 2007;6(12):895-900.

13. Kuo L, Godeke GJ, Raamsman MJ, Masters PS, Rottier PJ. Retargeting of coronavirus by substitution of the spike glycoprotein ectodomain: crossing the host cell species barrier. J Virol. 2000;74:1393-1406.
14. Keeler CL, Reed KL, Nix WA, Gelb J. Serotype identification of avian infectious bronchitis virus by RT-PCR of the peplomer (S-1) gene. Avi Dis. 1998;42:275-284.

15. Pensaert M, Lambrechts $C$. Vaccination of induced at the trachea and kidney level by vaccine strains and Belgian nephropathogeni c isolates of avian infectious bronchitis virus. Avi Pathol. 1994;22:577-590. 